\title{
THERMODYANAMIC AND RHEOLOGICAL PROPERTIES OF SOLID-LIQUID SYSTEMS IN COAL PROCESSING
}

by

\author{
Vinayak N. Kabadi \\ Palakkal Mohandas \\ Jinsong Wang
}

\author{
Chemical Engineering Department \\ North Carolina A\&T State University \\ Greensboro, NC 27411
}

\section{U.S. Department of Energy Grant no. DE-FG22-91PC91300}

\section{DISCLAIMER}

\begin{abstract}
This report was prepared as an account of work sponsored by an agency of the United States Government. Neither the United States Government nor any agency thereof, nor any of their employees, makes any warranty, express or implied, or assumes any legal liability or responsibility for the accuracy, completeness, or usefulness of any information, apparatus, product, or process disclosed, or represents that its use would not infringe privately owned rights. Reference herein to any specific commercial product, process, or service by trade name, trademark, manufacturer, or otherwise does not necessarily constitute or imply its endorsement, recommendation, or favoring by the United States Government or any agency thereof. The views and opinions of authors expressed herein do not necessarily state or reflect those of the United States Government or any agency thereof.
\end{abstract}




\section{DISCLAIMER}

Portions of this document may be illegible in electronic image products. Images are produced from the best available original document. 


\section{A GROUP CONTRIBUTION METHOD FOR THE PREDICTION OF VISCOSITY OF COAL DERIVED LIQUIDS}

\section{BACKGROUND:}

Models available are not very accurate (up to $45 \%$ error)

No method available which considers molecular structure to predict viscosity, specifically for coal liquids

Most corresponding states methods use certain specific constants apart from $\mathrm{Tc}, \mathrm{Pc}, \omega$

Available group contribution methods cannot be extended to coal liquid model compounds (structures like Thiophene, Pyridine, furan, etc. are not considered at all)

GROUP CONTRIBUTION METHOD:

(Van Velzen et. al, Ind. Eng. Chem. Fundam, 11, 20, 1972)

Limited applicability to coal liquids

* Pyridine, thiophene, furan, pyrrole, polyhydroxy phenyl groups are not defined

* Does not consider condensed ring structures and heteroatom groups attached to condensed ring structures

* Overall error $=26.93 \%$ for model aromatic compounds 


\section{CRITERIA FOR THE NEW MODEL:}

* Up to $\mathbf{1 0 - 1 5 \%}$ error in the viscosity of coal liquids

* Use benzene ring as the basic building block

* Must consider the effect of molecular structure

* Must be feasible to extend to any type of coal liquid using functional group analysis

* Group contributions using functional groups as building blocks

* Must be reasonably simple

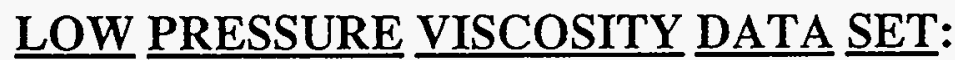

Model Compounds

No. of Compounds $=142$

No. of Data Points = 2339

Temperature range $=0.35 \leq \operatorname{Tr} \leq 0.70$

$\underline{\text { Binary }} \underline{\text { Mixtures }}$

No. of Mixtures $=73$

No. of Data Points $=2408$

$\underline{\text { Ternary and Multi Component }}$

No. of Mixtures $=6$

No. of Data Points $=48$ 
NEW VISCOSITY MODEL FOR PURE LIQUID AROMATICS:

$$
\log \eta=A+\frac{B}{T}
$$

where $\eta$ is absolute viscosity in centipoise

$\mathrm{T}$ is absolute temperature in ${ }^{0} \mathrm{~K}$

A and $B$ are obtained by group contribution method as follows

$$
\begin{gathered}
A=10\left[\left(\sum_{i} \triangle A_{i} \theta_{i}\right)_{r i n g}\left(N^{* *}\right)^{0.467}+\sum_{i} \triangle A_{i} n_{i}^{\alpha i}-1\right]+\triangle A_{a l k} \\
B=\left(\sum \triangle B_{i} \phi_{i}\right)_{r i n g}\left(N^{*}\right)^{-0.5}+\sum_{i} \triangle B_{i} n_{i}^{\beta i}+\triangle B_{a l k}
\end{gathered}
$$

In both the above expressions, the first summation is over group contributions of various ring structures. Types of ring groups considered are aromatic (ar), cyclopentane (cp), cyclohexane (ch), pyridine ( py), thiophene (th), cyclopentene (cpe), cyclohexene (che), pyrrole (pyr), furan (fu) and tetrahydrofuran (thf). Primary contribution of each of these rings $\left(\Delta \mathrm{A}_{\mathrm{i}}\right)$ is given in Table $1 . \theta_{\mathrm{i}}$ and $\phi_{\mathrm{i}}$ represent multiplication factors to the primary group contributions. $\Delta A_{i}$ and $\Delta B_{i}$ corresponding to the way ring $i$ is attached to other rings in a composite fused ring structure. Factors $\theta_{\mathrm{i}}$ and $\phi_{\mathrm{i}}$ for various ring configurations are given in Table 2. Let $N_{t}$ be the total number of rings in the molecule.

For $N_{t}=1, N^{*}=1$ and $N^{* *}=1$

For $\mathrm{N}_{\mathrm{t}}>1$

$\mathrm{N}^{*}=\left(\mathrm{N}_{\mathrm{ar}}+\mathrm{N}_{\mathrm{cp}}+1.9 \mathrm{~N}_{\mathrm{ch}}+.68 \mathrm{~N}_{\mathrm{py}}+2.8 \mathrm{~N}_{\mathrm{th}}+0.75 \mathrm{~N}_{\mathrm{cpe}}+\mathrm{N}_{\mathrm{che}}+\mathrm{N}_{\mathrm{pyr}}+\mathrm{N}_{\mathrm{fu}}+\mathrm{N}_{\mathrm{thf}}\right)$ $\mathrm{N}^{* *}=\left(\mathrm{N}_{\mathrm{ar}}+0.75 \mathrm{~N}_{\mathrm{cp}}+1.33 \mathrm{~N}_{\mathrm{ch}}+0.8 \mathrm{~N}_{\mathrm{py}}+2.4 \mathrm{~N}_{\mathrm{th}}+\mathrm{N}_{\mathrm{cpe}}+\mathrm{N}_{\mathrm{che}}+\mathrm{N}_{\mathrm{pyr}}+\mathrm{N}_{\mathrm{fu}}+\mathrm{N}_{\mathrm{thf}}\right)$

The contributions corresponding to phenyl linkages as in biphenyl and terphenyl must be added in the summations over the ring contributions.

For both $\mathrm{A}$ and $\mathrm{B}$, the second summation is over all the other non-ring groups in Table 1. $n_{i}$ represents number of groups of type $i$, and $\alpha_{i}$ and $\beta_{i}$ are exponents which are all unity except for the -OH group for which $\alpha_{i}=0.1$ and $\beta_{\mathrm{i}}=0.5$ 
Model for $(\Delta \mathrm{A})_{\mathrm{alk}}$ and $(\Delta \mathrm{B})_{\mathrm{alk}}$ :

$(\triangle A)_{\text {alk }}$ and $(\Delta B)_{\text {alk }}$ are contributions to $\mathbf{A}$ and $\mathbf{B}$ of all the alkyl groups attached to the rings excluding the $\alpha$-alkyl groups. These groups are treated equivalent to alkyl groups in normal paraffins. From experimental data on normal paraffins following model for $A_{\text {par }}$ and $B_{\text {par }}$ was obtained

$$
\begin{gathered}
A_{\text {par }}=10\left[0.5246+0.1657 e^{-0.2083 n_{c}}-1\right] \\
B_{\text {par }}=2392.82\left[1-e^{-0.08 n_{c}}\right]
\end{gathered}
$$

where $\mathbf{n}_{\mathbf{c}}$ is the number of carbon atoms in the paraffin.

Comparing A's and B's of paraffins and alkylbenzenes, it was observed that in tercept $A$ for an alkylbenzene is equivalent to that of a paraffin with carbon number three less than that of the alkylbenzene whereas slope $B$ for an alkylbenzene is equivalent to that of a paraffin with same number of carbon atoms as the alkylbenzene.

From this the following procedure is developed to calculate $(\Delta \mathrm{A})_{\mathrm{alk}}$ and $(\Delta \mathrm{B})_{\text {alk }}$. Let $n_{t}$ be the sum of all the ring carbon atoms and the alkyl chains carbon atoms in the molecule.

Let $n_{r}$ be the sum of all the ring carbon atoms and the carbon atoms in $\alpha$-alkyl groups. Then $(\Delta A)_{\text {alk }}$ and $(\Delta B)_{\text {alk }}$ are contributions of $\left(n_{t}-n_{r}\right)$ alkyl groups in the molecule and are given as

$(\Delta \mathrm{A})_{\mathrm{alk}}=\left(\mathrm{A}_{\mathrm{par}}\right)_{\mathrm{nc}=\mathrm{nt}-3}-\left(\mathrm{A}_{\mathrm{par}}\right)_{\mathrm{nc}=\mathrm{nr}-3}$

$(\Delta B)_{\text {alk }}=\left(B_{\text {par }}\right)_{\text {nc }=n t}-\left(B_{\text {par }}\right)_{\text {nc }=n r}$

\section{RESULTS:}

Comparison of model results with experimental data is shown in Table 3. An average percent error of $11.64 \%$ for 2605 data points indicates good agreement. 
Table 1

PRIMARY GROUPS AND THEIR CONTRIBUTIONS

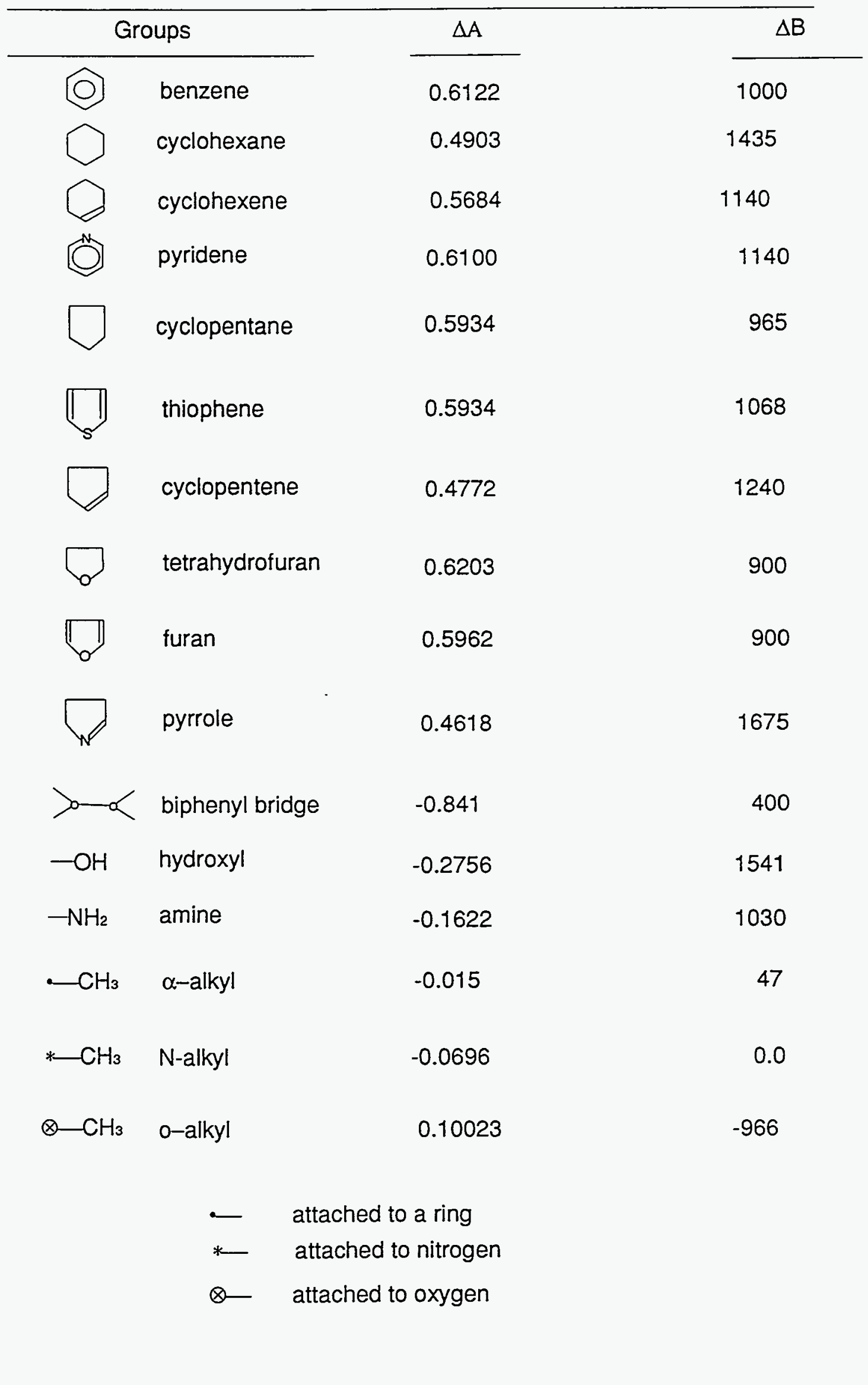


TABLE 2

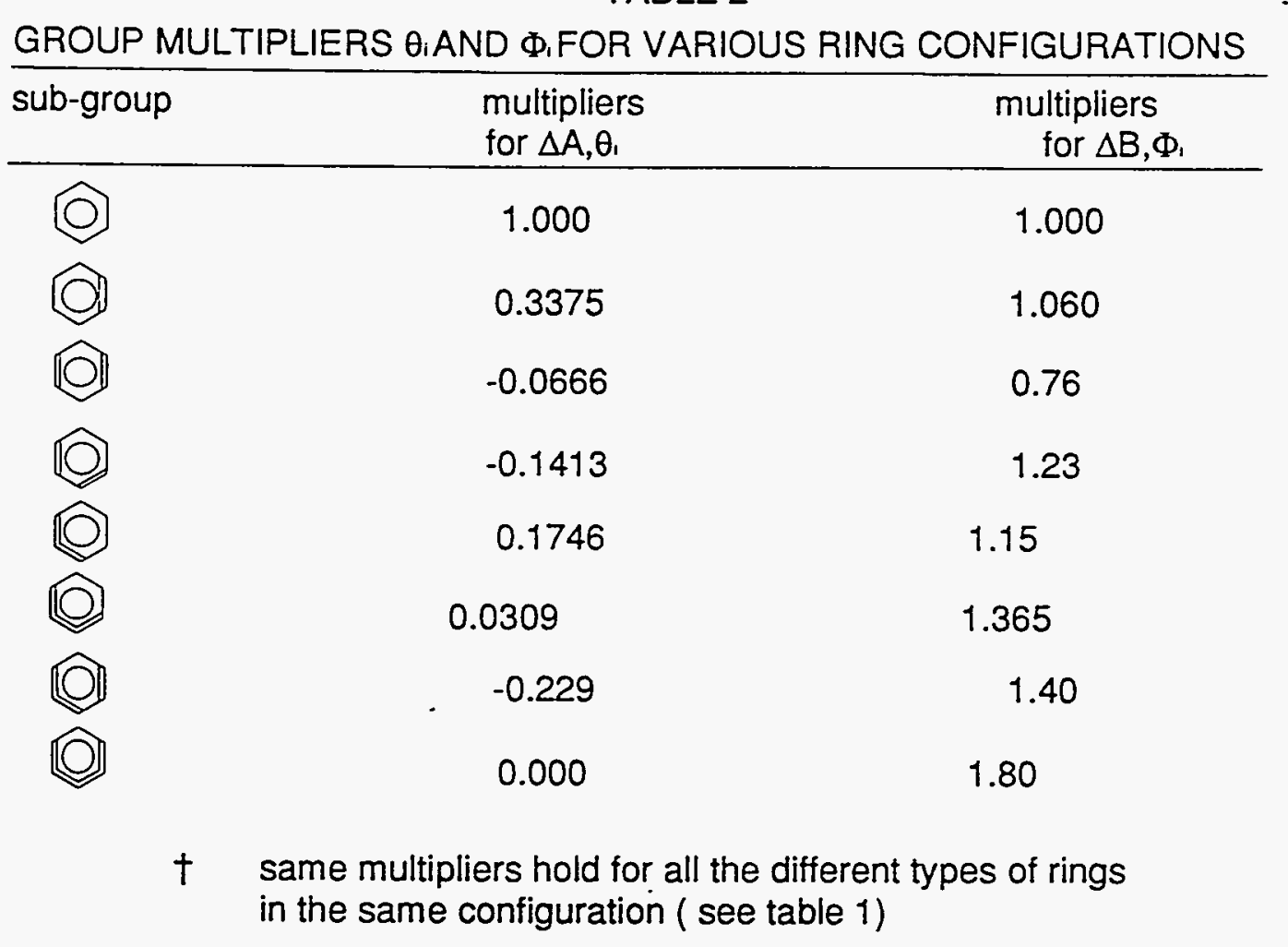

Table 3

ERROR ANALYSIS FOR HOMOLOGOUS SERIES

Homologous Series

n-Alkanes

Alkylbenzenes

Fused/multi ring compounds

Cyclohexanes

Phenols

Amines

Thiophenes

Pyridines

Cyclopentanes

Sidechain-linked compounds

Entire Data Bank
No. Of Points

$$
567
$$

483

550

253

232

259

37

141

77

6

2605 \%error

7.45

12.39

9.34

15.92

19.67

14.98

2.24

10.22

10.58

7.29

11.64 


\section{ILLUSTRATION OF VISCOSITY CALCULATION USING THE MODEL:}

Compound: Flouranthene

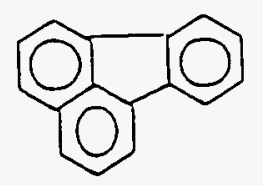

Required to calculate viscosity at $179.1^{\circ} \mathrm{C}$ of $452.25^{\circ} \mathrm{K}$

Step 1: Analysis of number of types of rings

Total number of rings $=4$

Type of rings: Aromatic $=3$, cyclopentane $=1$

$\mathrm{N}^{*}=3+1=4$

$\mathrm{N}^{* *}=3+0.75=3.75$

Step 2: Analysis of ring configurations and calculation of their contributions to $A$ and $B$

Rings
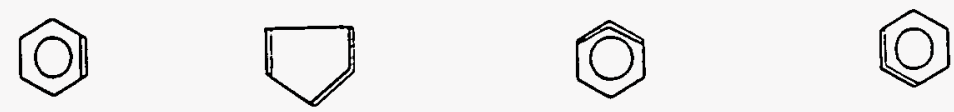

\begin{tabular}{lllll}
$\Delta \mathrm{A}_{\mathbf{i}}$ & 0.6122 & 0.5934 & 0.6122 & 0.6122 \\
$\Delta \theta_{\mathbf{i}}$ & 0.3375 & -0.229 & 0.1746 & 0.1746 \\
$\Delta \mathrm{B}_{\mathbf{i}}$ & 1000 & 950 & 1000 & 1000 \\
$\phi_{\mathbf{i}}$ & 1.06 & 1.40 & 1.15 & 1.15 \\
$\Delta \mathrm{A}_{\mathbf{i}} \theta_{\mathbf{i}}$ & 0.20661 & -0.1359 & 0.1069 & 0.1069 \\
$\Delta \mathrm{B}_{\mathbf{i}} \phi_{\mathbf{i}}$ & 1060 & 1330 & 1150 & 1150 \\
\hline
\end{tabular}

$$
\left(\sum_{i} \Delta A_{i} \theta_{i}\right)_{\text {ring }}=0.2845,\left(\sum_{i} \Delta B_{i} \phi_{i}\right)_{\text {ring }}=4690
$$

Step 3: From the equations for $A$ and $B, A=-4.7256, B=2345$

Step 4: With these $A$ and $B$ and $T=452.25^{\circ} \mathrm{K}$

$\eta=1.583 \mathrm{cp}$

From literature, experimental value is $1.528 \mathrm{cp}$, Error $=3.6 \%$ 
EXTENSION OF THE MODEL TO MIXTURES:

1. Kendall and Monroe (KM) Mixing rule:

$$
\mu_{M}=\left\{\sum x_{i} \mu_{i}^{1 / 3}\right\}^{3}
$$

\section{Quadratic Mean (QM) Mixing rule:}

$$
\mu_{M}=\sum_{i} \sum_{j} x_{i} x_{j}\left(\mu_{i} \mu_{j}\right)^{1 / 2}
$$

TABLE 4

ERROR ANALYSIS FOR BINARY SYSTEMS OF COAL LIQUID MODEL

\begin{tabular}{|c|c|c|c|c|c|}
\hline \multirow[t]{2}{*}{ SYSTEM } & \multirow[t]{2}{*}{ No.Pts } & \multicolumn{2}{|c|}{ QUADRATIC } & \multicolumn{2}{|c|}{ KENDALL-MONROE } \\
\hline & & experimental & model & experimental & model \\
\hline Aromatics-Aromatics & 553 & 1.70 & 9.27 & 1.68 & 9.22 \\
\hline Aromatics—Naphthenes & 187 & 10.45 & 6.43 & 10.22 & 6.38 \\
\hline Aromatics-Multiring compds & 162 & 4.95 & 6.19 & 4.56 & 5.91 \\
\hline Aromatics - Phenols & 18 & 88.73 & 59.57 & 67.93 & 45.20 \\
\hline Aromatics-Thiophenes & 11 & 0.28 & 2.39 & 0.28 & 2.39 \\
\hline Naphthenes-Multiring compds & 11 & 2.84 & 47.87 & 2.32 & 50.82 \\
\hline Phenols_Phenols & 69 & 2.09 & 36.37 & 1.86 & 36.38 \\
\hline Phenols-Pyridenes & 548 & 25.44 & 23.12 & 21.21 & 23.84 \\
\hline Phenols_-Amines & 335 & 13.06 & 31.10 & 13.30 & 30.88 \\
\hline Pyridenes-Amines & 64 & 12.95 & 16.76 & 13.11 & 16.90 \\
\hline Paraffins - Ring compounds & 59 & 8.55 & 10.54 & 8.20 & 10.25 \\
\hline Systems with Biphenyls & 118 & 7.30 & 35.93 & 7.34 & 35.73 \\
\hline Systems with guaiacols & 78 & 36.68 & 30.58 & 34.57 & 28.88 \\
\hline Entire Data bank & 2213 & 13.03 & 19.38 & 11.72 & 19.30 \\
\hline
\end{tabular}
COMPOUNDS 


\section{EQUATION OF STATE AT HIGH PRESSURES FOR LIQUID AROMATIC COMPOUNDS}

\section{OBJECTIVES:}

1. To develop an equation of state for high pressure liquid aromatic compounds, such as the ones that occur in coal liquids.

2. In addition to high pressure compressibilities, the equation should predict other thermodynamic properties of liquids such as enthalpies and heat capacities with reasonable accuracy.

3. Extend the equation to liquid mixtures, using the available low pressure models.

\section{ACHIEVEMENTS:}

1. A new saturated vapor pressure equation, which will be used in high pressure equation of state, was developed based on 127 organic compounds, 2971 data points.

2. A new correlation for saturated density, which will be used in high pressure equation of state was developed based on 124 organic compounds.

3. An extensive literature search was carried out for the high pressure liquid thermodynamic properties of organic compounds. 


\section{HIGH PRESSURE EQUATION OF STATE:}

The most promising of the equations in the literature is the Tait equation (Thomson et al. AICHE J., 28, 671, 1982)

$$
V=V_{s}\left(1-C \ln \frac{B+P}{B+P_{s}}\right)
$$

where $V_{s}$ is the saturated liquid volume at the saturation pressure $P_{s}$, $B$ and $C$ are parameters which for a given compound are functions of only temperature.

Using the detailed density and heat capacity data of benzene and toluene compiled by Goodwin (J. Phys. Chem. Ref. Data 17, 1541, 1988; Ibid 18, 1565,1989 ), Thomson equation was tested and following were the conclusions of the investigations.

1. Densities computed from Thomson equation agreed reasonably well with experimental data (errors $<1 \%$ for $\mathrm{T}_{\mathrm{r}}<0.9$ )

2. Errors in density exhibited definite trend with temperature showing a point of inflexion for benzene at about $450{ }^{\circ} \mathrm{K}$.

3. Trends in error with temperature, would indicate that larger errors would be expected for enthalpies and heat capacities because enthalpy is a function of first derivative of density with temperature and heat capacity is a function of the second derivative.

4. This was confirmed when experimental and calculated heat capacities of benzene were compared. Errors in calculated heat capacities (in excess of the values at saturation pressure) were found to exceed $100 \%$ over the entire temperature range, with a very good agreement observed at $450{ }^{\circ} \mathrm{K}$ as expected.

5. To identify the source of the temperature dependence of the density errors, the methods used for $P_{s}$ ( Lee-Kesler equation) and $V_{s}$ (Rackett equation) were tested. Although, these methods were found to give some 
errors, no systematic trends were observed. Next B and C were regressed at different temperatures from experimental data. Definite deviations were observed between these values and equivalent curves in Thomson equation.

6. Based on above results, the following three tasks were undertaken

(a) Develop a better generalized correlation for vapor pressures to be valid from melting point to critical point.

(b) Improve and generalize the Rackett equation for saturated densities.

(c) Obtain better expressions for Tait B and C using density and heat capacity data.

\section{NEW VAPOR PRESSURE EQUATION:}

An accurate vapor pressure correlation is needed for $P_{s}$ in Tait equation. No accurate vapor pressure correlations is available from melting point to critical point. Based on the formula of Pitzer (J. Am. Chem. Soc. 77, 3433, 1955) and Wagner equation (Cryogenics 13, 470, 1973), we developed a new saturated vapor pressure equation.

$$
\begin{gathered}
\ln (P / P c)=f^{(B)}\left(T_{r}\right)+\Phi f^{(c)}\left(T_{r}\right) \\
f^{(B)}\left(T_{r}\right)=\left(a_{B} x+b_{B} x^{1.5}+C_{B} x^{3}+d_{B} x^{6}\right) / T_{r} \\
f^{(c)}\left(T_{r}\right)=\left(a_{c} x+b_{c} x^{1.5}+C_{c} x^{3}+d_{c} x^{6}\right) / T_{r}
\end{gathered}
$$

where $f^{(B)}\left(T_{r}\right)$ is the vapor pressure of benzene, $f^{(c)}\left(T_{r}\right)$ represents departure from vapor pressure of benzene and $x=\left(1-T_{r}\right)$.

Regressed constants for these equations are given below.

$a_{B}=-6.958, b_{B}=1.2776, c_{B}=-2.5647, d_{B}=-3.4035, a_{c}=-1.2731$, $b_{c}=-0.2194, c_{c}=-0.2638, d_{c}=-4.4878$

$\Phi$ is a compound specific parameter. Three different methods were devised for $\Phi$ (Methods 2-4 below) 
Four Methods:

Method 1: Specific constants a, b, c, d regressed for each compound using Wagner's equation.

Method 2: Specific $\Phi$ regressed for each compound using experimental data.

Method 3: $\Phi$ calculated for each compound from one data point $(\operatorname{Tr}=0.6)$

Method 4: Group contribution method to estimate $\Phi$.

Group contribution method for $\Phi$ :

We note the vapor pressure is strongly related to the shape of the molecule. So we defined a parameter $\Psi$ which is called shape factor.

$$
\Psi=\frac{S_{\text {compound }} /\left(V_{\text {compound }}\right)^{2 / 3}}{S_{\text {benzene }} /\left(V_{\text {benzene }}\right)^{2 / 3}}
$$

$V$ is the summation of $R$ as in UNIFAC.

$\mathrm{S}$ is the summation of $\mathrm{Q}$ as in UNIFAC with some modifications, and additions of ring, branch, and attachment factors.

Groups, group contributions $R$ and $Q$ and all the relevant addition and multiplication factors are given in Tables 5,6 , and 7 .

The following expression was fitted to the values of $\Phi$ and $\Psi$ :

$\Phi=a_{1}(1-\Psi)+a_{2}(1-\Psi)^{2}+a_{3}(1-\Psi)^{3}$

$\mathrm{a}_{1}=-4.2546, \mathrm{a}_{2}=4.5345, \mathrm{a}_{3}=7.2866$

Figure 1 shows a very good correlation between regressed $\Phi$ and the shape factor $\Psi$ : 
Table 5 . List of R and Q of Different Groups

\begin{tabular}{|c|c|c|c|c|}
\hline I.D. & Group Symbol & $\mathrm{R}$ & $\mathrm{Q}_{\text {(this paper) }}$ & $Q_{\text {(UNIFAC) }}$ \\
\hline g1 & $\mathrm{CH}_{3}$ & 0.9011 & 0.8480 & 0.848 \\
\hline g2 & $\mathrm{CH}_{2}$ & 0.6744 & 0.5400 & 0.540 \\
\hline g3 & $\mathrm{CH}$ & 0.4469 & 0.2280 & 0.228 \\
\hline g4 & $\mathrm{C}$ & 0.2195 & 0.0000 & 0.000 \\
\hline g5 & $\mathrm{OH}$ & 1.0000 & 1.7700 & 1.200 \\
\hline g6 & $\mathrm{aCH}^{(+)}$ & 0.5313 & 0.4000 & 0.400 \\
\hline g7 & $\mathrm{aCC}^{(*)}$ & 0.5847 & 0.0000 & 0.120 \\
\hline g8 & $\mathrm{aC}$ & 0.3652 & 0.1200 & 0.120 \\
\hline g9 & $\mathrm{aCOH}$ & 0.8952 & 1.2562 & 0.680 \\
\hline g10 & $\mathrm{CH}=\mathrm{CH}$ & 1.1167 & 0.8670 & 0.867 \\
\hline g11 & $\mathrm{aCNH}^{(*)}$ & 0.8978 & 0.5332 & 0.516 \\
\hline $\mathrm{g} 12$ & $\mathrm{aCNH}_{2}$ & 1.0600 & 1.1975 & 0.816 \\
\hline g13 & $\mathrm{aCBr}$ & 1.3144 & 0.9611 & 0.952 \\
\hline g14 & $\mathrm{aCCl}$ & 1.1562 & 0.8442 & 0.844 \\
\hline g15 & $\mathrm{aCCOOH}$ & 1.6665 & 2.1967 & 1.344 \\
\hline $\mathrm{g} 16$ & $\mathrm{aC}-\mathrm{O}-\mathrm{CH}_{3}$ & 1.5102 & 1.3462 & 1.208 \\
\hline g17 & $\mathrm{aC}-\mathrm{O}-\mathrm{CH}_{2}$ & 1.2835 & 1.1031 & 0.900 \\
\hline $\mathrm{g} 18$ & $\mathrm{aC}-\mathrm{CH}=\mathrm{CH}_{2}$ & 1.7106 & 1.2068 & 1.296 \\
\hline g19 & $\mathrm{aN}^{(*)}$ & 0.3428 & 0.3675 & 0.113 \\
\hline $\mathrm{g} 20$ & $\mathrm{NH}^{(*)}$ & 0.5326 & 0.7742 & 0.369 \\
\hline $\mathrm{g} 21$ & $\mathrm{aO}^{(*)}$ & 0.2439 & 0.2706 & 0.240 \\
\hline $\mathrm{g} 22$ & as ${ }^{(*)}$ & 0.91875 & 0.6747 & 0.825 \\
\hline
\end{tabular}

Note, ${ }^{(+)}$: All groups starting with "a" are aromatic groups

${ }^{(*)}$ : For these groups UNIFAC R and Q were estimated from other group contributions. 
Table $6 \mathrm{Q}$ Additives $\left(Q_{\text {add }}\right)$ for Various Molecular Structure

\begin{tabular}{llc}
\hline I.D. & \multicolumn{1}{c}{ Structure } & Q Qdd \\
r1 & One aromatic-ring & 0.45023 \\
r2 & Two aromatic -ring & 0.71355 \\
r3 & Three aromatic-ring & 1.10481 \\
r4 & Four aromatic-ring & 1.23800 \\
r5 & One aromatic -one napthene (fused) & 0.60446 \\
r6 & Two aromatic -one naphthene (fused) & 1.01571 \\
r7 & Cyclohexane (without attachment) & 0.102451 \\
r8 & Cyclohexane (with attachment) & -0.118173 \\
r9 & Isoquinoline & -0.13794 \\
\hline
\end{tabular}

Table 7: Modifications to $Q$ for some additional Group Structures ${ }^{+}$

\begin{tabular}{llll}
\hline Group g & $Q_{\text {add }}$ & $\Theta_{\mathrm{a}}$ & $\Theta_{\mathrm{b}}$
\end{tabular}

$-\mathrm{CH}_{3}$ branch

eg. --C.--

$-0.08289$

2 , if two branches

1.0

attached to same carbon

0.5 , if a single branch in

$\beta$ position relative to a ring

1.0 , all other cases

$--\mathrm{CH}_{2}-\mathrm{CH}_{3}$ branch $\quad-0.1233$

Same as for $-\mathrm{CH}_{3}$ branch

1.0

eg. - - $\mathrm{C}$--<smiles>CCC</smiles>

Attachments to

0

0.9872

an aromatic ring

in ortho position

Two attachments to

0

0.9461

a carbon in a hydro-

aromatic ring

Alkyl groups in the

$-0.02157$

1.0

1.0 largest straight chain attached to a ring

$+Q_{M}=\left(Q_{g}+Q_{a d d} \Theta_{a}\right) n_{g} \Theta_{b}$

$Q_{M}$. modified contribution of $n_{g}$ groups of type $g$

$Q_{g^{-}}$original contribution (Table 4) per group of type $g$ 


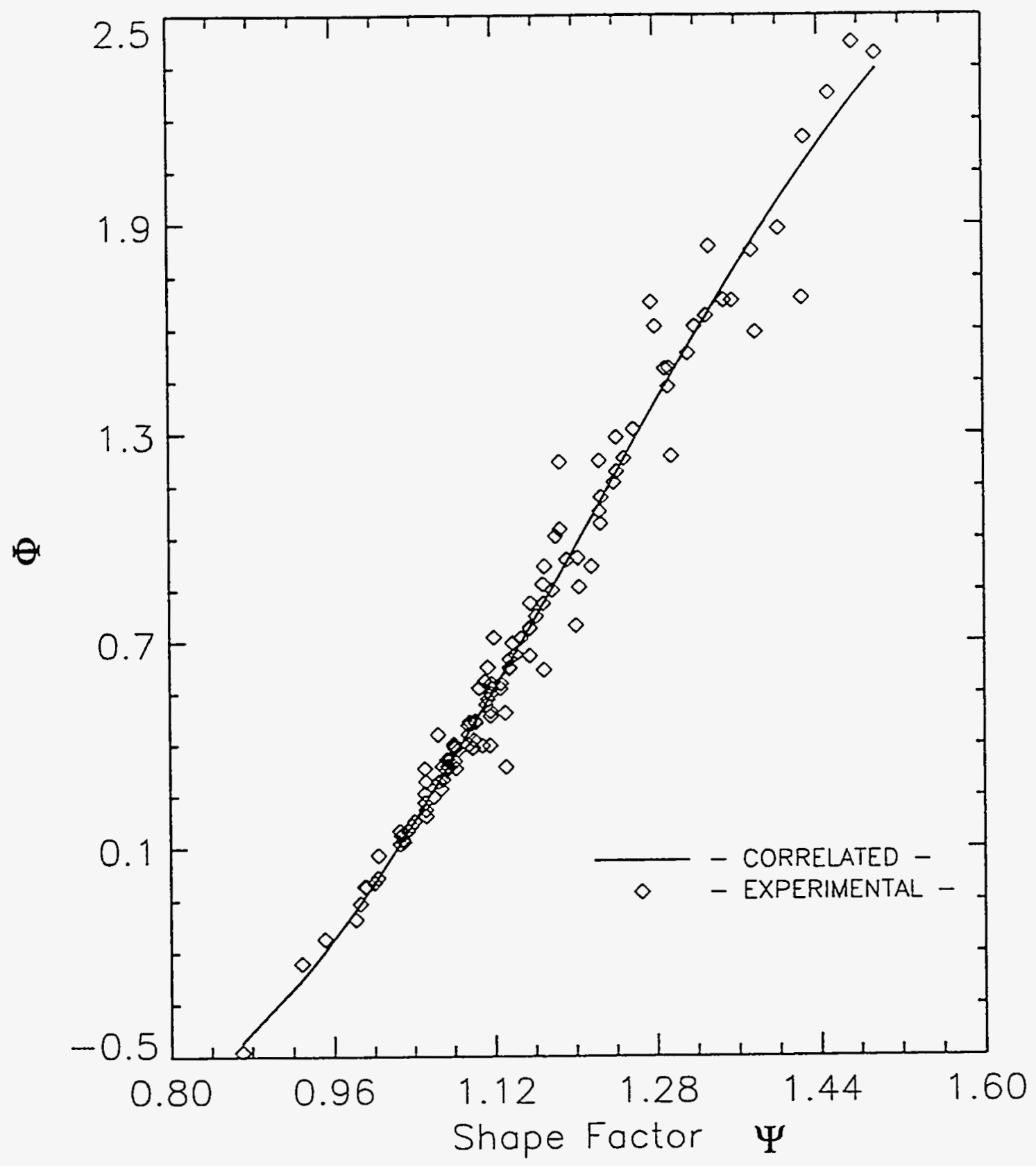

FIGURE 1 


\section{RESULTS:}

Comparison of the correlations (Methods 1-4 and Lee-Kesler) with experimental data for different homologous series of compounds is shown in Table 8.

Comparisons of the correlations around the melting point and the boiling point are shown in Table 9.

Results are impressive. Even the generalized correlation (Method 4) performs as well as the Lee-Kesler method, but with applicability over a wider range of temperatures.

\begin{tabular}{|c|c|c|c|c|c|c|}
\hline & Method 1 & Method 2 & Method 3 & Method 4 & Lee-Kesler & No. Pts \\
\hline 1.alkanes & 0.260 & 1.96 & 2.63 & 3.07 & 3.17 & 906 \\
\hline 2.alcohols & 0.088 & 5.75 & 8.46 & 16.24 & 9.62 & 185 \\
\hline $\begin{array}{l}\text { 3.alkyl- } \\
\text { benzenes }\end{array}$ & 0.210 & 1.12 & 1.27 & 3.37 & 3.34 & 706 \\
\hline 4.phenols & 0.884 & 4.39 & 7.60 & 7.47 & 4.89 & 218 \\
\hline $\begin{array}{c}\text { 5.alkyl cyclo- } \\
\text { hexanes }\end{array}$ & 0.141 & 1.33 & 1.45 & 3.78 & 4.07 & 174 \\
\hline $\begin{array}{l}6 . \text { two ring } \\
\text { aromatics }\end{array}$ & 0.612 & 3.10 & 4.03 & 6.98 & 12.60 & 298 \\
\hline $\begin{array}{l}\text { 7.three and } \\
\text { four ring } \\
\text { aromatics }\end{array}$ & 0.724 & 6.76 & 9.54 & 17.23 & 17.85 & 173 \\
\hline Total & 0.360 & 2.53 & 3.45 & 5.65 & 5.55 & 2971 \\
\hline
\end{tabular}

\begin{tabular}{|l|c|c|c|c|c|}
\hline \multicolumn{1}{|c|}{ Table 9. Comparison of Correlations In Different Temperature Ranges } \\
\hline Temperature Range & No. Points & Method 2 & Method 3 & Method 4 & Lee-Kesler \\
\hline Tm<T<Tm +30K & 100 & $8.06 \%$ & $15.65 \%$ & $13.70 \%$ & $20.29 \%$ \\
\hline T nearest to Tb & 127 & $3.15 \%$ & $2.92 \%$ & $5.01 \%$ & $2.54 \%$ \\
\hline
\end{tabular}


Rackett ( J. Chem. Eng. Data, 15, 514, 1970)] developed an equation to estimate saturated volumes. The equation was later modified by Spencer and Danner (J. Chem. Eng. Data, 17, 236, 1972). In this correlation specific $\mathrm{Z}_{\mathrm{RA}}$ was used for each compound. Yamada (J. Chem. Eng Data 18, 234, 1973) proposed a method to estimate $Z_{R A}$ from acentric factors. We developed a method to calculate $Z_{\mathrm{RA}}$ from Van der Waals volumes.

$Z_{R A}=\frac{P_{c}}{R T_{c}}\left(2.768858+0.423611 V_{w}+9.2792939 \times 10^{-4} V_{w}^{2}\right)$ where $P_{c}$ is in bars, $T_{c}$ is in ${ }^{\circ} \mathrm{K}, R=8.314 \mathrm{bar} c \mathrm{~mole}{ }^{0} \mathrm{~K}$ and $V_{\mathrm{w}}$ is in cc/mole.

\section{RESULTS:}

Comparisons of Regressed $\mathrm{Z}_{\mathrm{RA}}$ with ones obtained from the Yamada and our correlation are shown in Table 10. It is observed that Van der Waals volume is a better correlation parameter than acentric factor. For 782 data points for $\mathbf{4 0}$ liquids, the correlations gave the following percent errors:

Regressed $\mathrm{Z}_{\mathrm{RA}}-\mathbf{0 . 5 6 \%}$, Yamada $\mathrm{Z}_{\mathrm{RA}}-5.87 \%$, Our $\mathrm{Z}_{\mathrm{RA}}-\mathbf{3 . 9 6 \%}$ $A$ better generalized method for saturated liquid densities has thus been developed.

\begin{tabular}{|l|c|c|c|}
\hline Table 10 Comparison between Yamada Correlations and Our Method for Prediction of ZRA \\
\hline & $\begin{array}{l}\text { No. of } \\
\text { Points }\end{array}$ & Yamada & Ours \\
\hline Paraffins & 34 & 1.692 & 1.429 \\
\hline Halogenated Paraffins & 6 & 4.815 & 2.833 \\
\hline Cycloparaffins & 4 & 0.316 & 0.319 \\
\hline Olefins & 13 & 1.549 & 2.119 \\
\hline Aromatics & 26 & 2.781 & 2.565 \\
\hline Aromatic Derivatives & 4 & 1.474 & 1.263 \\
\hline Heterocycles & 8 & 2.021 & 1.439 \\
\hline Alcohols & 8 & 4.834 & 1.416 \\
\hline Phenols & 9 & 6.954 & 3.113 \\
\hline Amines & 7 & 2.673 & 2.133 \\
\hline Ethers & 3 & 0.717 & 2.759 \\
\hline Sulfides & 2 & 1.259 & 0.940 \\
\hline Total & 124 & 2.636 & 1.953 \\
\hline
\end{tabular}

